\title{
Mortality differentials 1991-2005 by self-reported ethnicity: findings from the ONS Longitudinal Study
}

\author{
Anne P Scott, ${ }^{1}$ Ian M Timæus² \\ 1 Unaffiliated researcher \\ 2 Department of Population Health, London School of Hygiene \& Tropical Medicine, \\ London, UK
}

Correspondence to Professor Ian Timæus, Department of Population Health, London School of Hygiene \& Tropical Medicine, Keppel Street, London, WC1E 7HT, UK; ian.timaeus@lshtm.ac.uk; Tel: 020-7299 4689.

Keywords differential mortality; England/epidemiology; ethnic groups/statistics \& numerical data; immigrants; minority health/statistics \& numerical data.

\section{Licence for Publication}

The Corresponding Author has the right to grant on behalf of all authors and does grant on behalf of all authors, an exclusive licence on a worldwide basis to the BMJ Publishing Group Ltd to permit this article (if accepted) to be published in JECH and any other BMJPGL products and sublicences such use and to exploit all subsidiary rights, as set out in our licence (http://group.bmj.com/products/journals/instructions-forauthors/wholly_owned_licence.pdf).

Competing Interest: None declared. 


\section{ABSTRACT}

Background Research on ethnic differentials in mortality in England and Wales has focused on immigrants because, until now, studies collecting data on ethnicity have not covered sufficient deaths to investigate the subject. International migrants are selected for good health and tend to have low mortality.

Methods We investigated all-cause mortality at ages 1-79 in 1991-2005 by self-reported ethnicity and country of birth. The data are from the ONS Longitudinal Study of England and Wales for the cohort aged 0-64 in 1991 ( $n=436$ 195). Poisson regression was used to adjust the estimates for metropolitan residence and three indicators of socioeconomic status.

Results White, Black Caribbean, Other Asian and Other immigrants all had lower mortality than Whites born in the UK. Indian, Pakistani, Bangladeshi and Chinese immigrants had lower mortality than UK-born Whites living in similar circumstances to them. By contrast, the UK-born Black Caribbean group had higher mortality ( $R R=1.38,95 \%$ CI 1.03 to 1.86 ) than UK-born Whites. This excess mortality was accounted for by their low socioeconomic status. Within the Black Caribbean population, UK-born individuals had significantly higher mortality than those born abroad whether or not the estimates were adjusted for socioeconomic status and metropolitan residence. Adjusting exposure time for undocumented emigration made little difference to the estimates.

Conclusion Immigrants are selected for good health. This has offset the impact of socioeconomic disadvantage on the mortality of minority ethnic groups. As the immigrant population ages and UKborn minority ethnic population grows, ethnic differentials in all-cause mortality are likely to change. 


\section{INTRODUCTION}

Research into the mortality of minority ethnic populations in England and Wales is limited because no information on ethnicity is collected on death certificates.[1] Until 1991, no information on ethnicity was available from the Census either. Moreover, because minority ethnic groups are both a small proportion of the entire population and relatively young, most sample-based inquiries cover too few deaths to study ethnic differentials in mortality.

Several earlier studies have investigated mortality by country of birth.[2-7] A crosssectional analysis for 2001-2003 found that all-cause mortality is often lower among adults born abroad than for the population born in England and Wales. For example, this was true for men born in India and China and Hong Kong, and women born in the West Indies, West Africa and China and Hong Kong.[7] One explanation of such findings is that international migrants are selected for good health.[2,8] This is often termed the "healthy migrant effect'. Moreover, return migrants may be selected for poor health - 'the salmon bias'. $[9,10,1]$ In addition, the mortality of different ethnic groups has been estimated from 2001 Census data on limiting long-term illness.[11] These estimates suggest that most minority ethnic groups except the Chinese have higher mortality than the White population, with the Pakistani and Bangladeshi groups doing particularly badly.

This paper describes variations in mortality in England and Wales in 1991-2005 by self-reported ethnicity and country of birth using data from the Office for National Statistics (ONS) Longitudinal Study (LS). It distinguishes the mortality of immigrants from that of UK-born individuals for each ethnic group, investigates what part of the differences in mortality according to birthplace and ethnicity is accounted for by commonly used indicators of socioeconomic status (SES), and assesses the impact of unobserved embarkations on estimates of mortality for minority ethnic groups. We hypothesize that, while first-generation immigrants are a select group with low mortality, their offspring will have higher mortality than the White UK-born majority because of their relatively low socioeconomic position. 


\section{METHODS}

\section{ONS Longitudinal Study}

The LS is a database that links census and vital events records from 1971 onward for $~ 1 \%$ of the population of England and Wales.[12] We studied the cohort of LS members traced in the National Health Service Central Register before or during 1991 Census processing who were aged $<65$ on the day of the 1991 Census and enumerated in private households (Table 1). This cohort was followed up in the death registers from census day to the end of 2005 , by when it was aged 14-79. The minority ethnic population only accounts for a few of the deaths in earlier cohorts as only $3 \%$ of it was aged $65+$ in 1991. As most deaths of infants born in the year before the census will have pre-dated the census, we analysed mortality at ages 1-79.[13]

Individuals' ethnicity was defined by the household member(s) who completed the 1991 Census form using pre-coded tick boxes for the following groups: White, Indian, Black Caribbean, Pakistani, Black-African, Bangladeshi, Black Other, Chinese and Other. Further details were requested from those ticking either of the Other boxes. Our analyses used three indicators of the SES of households - housing tenure, car ownership and the National Statistics Socio-economic Classification.[14-17] All members of a family were assigned to the highest status parental occupation.[17] The analyses also took into account where people lived in 1991, distinguishing Inner and Outer London from other Metropolitan areas and Non-Metropolitan areas.

In addition to calculating descriptive statistics, we modelled the relative risk of dying according to various sets of characteristics by means of Poisson log-linear regression models for rates with person-years spent in the LS as the offset variable. All the estimates of mortality presented have been adjusted for five-year age group, sex, and date of exposure (1991-98 or 1999-2005). We also modelled the data using negative binomial models but found no evidence of over-dispersion (results not shown).

Exit from the LS occurs when individuals die or notify their doctor or Health Authority (HA) - subsequently Primary Care Organisation - that they are emigrating. An emigrant can re-enter the LS by re-registering with a HA. The calculation of the person- 
years that the cohort spent exposed to the risk took into account exits and re-entries. It also made allowance for undocumented emigration. In particular, using an algorithm developed for mortality research using the LS, it was inferred that individuals had emigrated if their HA cancelled their registration because they had not been in contact with their doctor for several years and they then failed to re-register with a doctor within a year. A full account of this algorithm is available elsewhere.[18]

Some additional undocumented emigrants will exist among the LS members who could not be accounted for at the 2001 Census despite not being known to have emigrated or died. These missed emigrants bias the death rates downward by inflating their denominators. To assess the potential impact of this, the key analysis is presented incorporating an adjustment for it, as well as with denominators adjusted only for reported embarkations and those inferred from HA de-registrations. Because it addresses the issue of unreported censoring by emigration, not unreported events, our approach differs from standard methods for addressing attrition and wave non-response in panel studies.[19-22]

The adjustment used logistic regression to model how much of the period between the 1991 Census and end of 2005 LS members who were either recorded as emigrating or identified in the 2001 Census spent outside the country as a function of their 1991 characteristics: age, sex, place of residence, SES measured by all three indicators we consider, ethnicity interacted with whether they were migrants, and the length of residence in the UK of immigrants. This model was then used to predict how much of each 7-year period under study the $10 \%$ of the cohort with no information after 1991 spent as emigrants. If the probability of undocumented embarkation was random conditional on the 1991 characteristics used to model it, this procedure will eliminate bias due to unrecorded loss to follow-up between the 1991 and 2001 Censuses.[23] Because no way yet exists of estimating undocumented emigration in 2001-05, no adjustment was made for it.

\section{RESULTS}

Table 1 presents basic descriptive information on the cohort. Of the LS sample aged $<65$ in 1991, >92\% described themselves as White. The largest minority ethnic groups were Indians, Pakistanis and those of Black Caribbean origin. About two-fifths of all non-White 
people were born in the UK, but only about one quarter of Bangladeshis, Chinese and Other Asians. Only $4 \%$ of the White cohort members were born abroad.

The age structure of the different ethnic groups varied. Like the distributions by place of birth, this reflects differences in fertility and in the dates and ages at arrival of immigrants. The Black African, Other Black, Pakistani, and Bangladeshi groups were least likely to be aged 65+. The White and Black Caribbean groups contained the most older people. Even so, the UK-born Black Caribbean group only had a mean age of $<19$ years in 1991, compared to 31 years for Whites born in the UK.

Information on the status of the cohort at the 2001 Census is shown in Table 2. Although $<11 \%$ of its members could not be accounted for in 2001 , this proportion is much larger than the proportions of the cohort that had died or exited the LS as a result of either a recorded embarkation or an HA de-registration. The proportion of the White UK-born group with a reported embarkation and the proportion de-registered by their HA were similar. The UK-born minority ethnic population were no more likely than Whites to have reported their departure, but almost three times more likely to have been de-registered. Individuals born abroad were over three times more likely to have left England and Wales than the UK-born, with emigrants identified from de-registrations greatly outnumbering reported embarkations. These figures, and the differentials between different minority ethnic groups, emphasize the importance of taking HA de-registrations into account in this analysis.

The final two columns of Table 2 show the estimated proportion of the follow-up period for which individuals not identified in the 2001 Census and not known to have died or emigrated were not at risk of dying in the UK because they had emigrated before 2001 . On average, this group spent $6.9 \%$ of the period of follow up as emigrants, compared to $2.7 \%$ for those who could be accounted for. However, $<23 \%$ of unaccounted for follow-up time was lost to emigration by even the immigrant component of every ethnic group.

Table 3 shows distributions of the different ethnic groups according to their SES and area of residence in 1991. Compared with the White majority, a small proportion of the minority ethnic populations belonged to higher-status socioeconomic groups and a large 
proportion to the Routine and Other (inactive and unemployed) categories. The non-white population as a whole was also disadvantaged in terms of car access and home ownership.

Not all minority ethnic populations were equally disadvantaged and the patterns revealed by the three indicators of SES differed. For example, Indians had higher rates of owner-occupation and car access than Whites and relatively large proportions of the Chinese group reported managerial, professional or intermediate occupations and lived in households that owned a car. The Pakistani group had a higher rate of owner-occupation than Whites, but often had either low-status occupations or no identified occupation. The Bangladeshi group was the most underprivileged in terms of their occupations and car ownership and relatively likely to live in socially-rented housing. The Black Caribbean and Other Black groups were also disadvantaged on all three indicators. The Black African group, on the other hand, was most likely to live in socially-rented housing and rather unlikely to own a car, but included quite a large number of people in managerial and professional occupations.

Low rates of car and home ownership among some minority ethnic groups may be related to their concentration in metropolitan areas. Two-thirds of Whites but less than one third of the minority ethnic population lived in non-Metropolitan areas (Table 3). The Black Caribbean, Black African and Bangladeshi groups were most likely to live in Metropolitan districts and, in particular, in Inner London. Few ethnic Indians and Pakistanis resided in Inner London, but similar proportions of Indians lived in Outer London and Other Metropolitan districts, whereas the Pakistani group was concentrated in the Other Metropolitan districts.

The risk of dying varies by both age and sex and declined in England and Wales between 1991 and 2005. A regression model predicting the death rates of the cohort from just these three factors found that the relative risk of dying rises rapidly with age, was 37\% lower among women than men, and was 13\% lower in 1999-2005 than 1991-1998. The more elaborate regression models presented in Tables 4 and 5 all control for these three confounders. 
Table 4 describes variations in mortality at ages 1-79. Individuals born outside the UK had 9\% lower mortality (95\% CI: 5-13\%) than the UK-born. All the minority ethnic groups except Black Africans had lower mortality than the White population. In particular, the mortality of the Black Caribbean population was 12\% lower (95\% CI: 1-23\%) and the lower mortality of the Other Asian and Other groups was also statistically significant.

There were steep gradients in mortality according to all the indicators of SES in 1991. The mortality of car owners, owner occupiers and those with managerial and professional occupations was much lower than that of other people. Mortality was higher in Inner London and the Other Metropolitan areas than in non-metropolitan England and Wales, but lower in Outer London than elsewhere in the country.

Table 5 presents estimates of the coefficients of three models. The first model examines how country of birth and ethnicity together affect mortality relative to the UKborn White population. The immigrants among the Black Caribbean and Other groups accounted for their significantly lower mortality than the UK-born White population. Whites born abroad also had lower mortality than Whites born in the UK. Focusing on the UK-born, the only minority ethnic group with significantly different mortality from Whites was the Black Caribbean population, which had 38\% higher mortality (95\% CI: 3-86\%).

The second model examines the net impact on mortality of ethnicity and country of birth adjusted for the impact of other factors. After controlling for all three measures of SES and place of residence, no significant ethnic differentials existed in mortality among the UK-born population. In particular, the excess mortality of the Black Caribbean population born in the UK was accounted for largely by socioeconomic disadvantage.

The third model contains the same explanatory variables, but reduces the personyears of observation to allow for undocumented embarkations of members of the cohort who are not known to have died or emigrated but could not be identified in the 2001 Census. This adjustment makes very little difference to the relative risks of dying of the different ethnic groups although, as expected, it slightly raises the mortality of some minority groups relative to the White UK-born population. 


\section{DISCUSSION}

Ethnic differentials in mortality remain difficult to investigate because ethnicity is not collected on death certificates in England and Wales although it has been asked about on a voluntary basis in Scotland since 2012.[24] The LS provides such information for England and Wales by linking the certificates to Census records but only covers $\sim 1 \%$ of the population. Our study benefited from being based on several more years of follow-up since 1991 than previous research using the LS, during which minority ethnic populations continued to grow and age.[1] Nevertheless, the sample of minority ethnic deaths remained rather small for study of this topic.

Unrecorded emigration of LS members who were not identified in the 2001 Census, but are not known to have died or emigrated, was estimated by assuming that all embarkations in the rest of the cohort had been identified and that individuals' propensity to migrate depends solely on their characteristics in 1991 as measured here. No adjustment was made for undocumented emigration during 2001-2005. Equally, some people that we classified as emigrants because they were no longer registered with a general practitioner will have remained in the country.[25] People with no linked records subsequent to 1991 were estimated to be 2.6 times more likely to emigrate by 2001 than the rest of the cohort. Nevertheless, adjusting the exposure time of this group downward affected the estimates of differential mortality only slightly because most of them did not emigrate and they comprised only $10 \%$ of the surviving cohort. Given the insensitivity of our results to the adjustment made for undocumented emigration, bias from this source is unlikely to have influenced the conclusions reached by this study.

Distinguishing immigrant and UK-born members of minority ethnic groups revealed that the Black Caribbean population born abroad had lower mortality in 1991-2005 than Whites born in the UK despite their lower SES in 1991. This result is consistent with the idea that migrants are selected for health. By contrast, the UK-born Black Caribbean population had higher mortality than Whites born in the UK. However, the $88 \%$ of the Other Black group that were UK-born included many people who were wholly or partly of Caribbean descent but described as "Black British" in the 1991 Census. They do not share the high mortality of those reported explicitly to be of Black Caribbean descent. 
The excess mortality of the UK-born individuals who were reported as of Black Caribbean descent is almost entirely accounted for by the indicators of SES included in the analysis. In other words, this group has relatively high mortality because it tends to be disadvantaged. Within the Black Caribbean population, individuals born in the UK have significantly higher mortality than immigrants. This differential is not accounted for by differences in their SES.

The regression model that adjusted for SES and residence showed that, in addition to Black Caribbean immigrants, Indian, Pakistani, Bangladeshi, Chinese, Other Asian and Other immigrants all had lower mortality than UK-born Whites who were living in similar circumstances to them. This advantage is only manifest in the unadjusted estimates for the Other Asian and Other groups. This suggests that immigrants from the Indian subcontinent and China are also selected for health, but that the impact of this on mortality has been offset by their social disadvantages compared with the UK-born White population.

Our findings refer to the population in private households enumerated at the 1991 Census and are based on self-reported ethnicity as coded then. The UK-born White population as identified in 1991 is itself ethnically diverse including, for example, the children of Irish parents and those of Romani extraction. Some of these hidden minority ethnic groups may have high mortality. Substantial immigration has occurred since 1991 and the results do not reflect the mortality of this part of the immigrant population. We also only examined the mortality of those aged $<65$ in 1991 . Thus, the cohort was still aged $<80$ at the end of follow up. Ethnic differentials in mortality from diseases that mainly affect older people may be patterned differently. In addition, the results do not reflect the mortality of children born after 1991, although few of these children will have died after infancy by 2005. The SES of cohort members was measured in 1991 and the relationship between SES then and earlier in life may differ between people born abroad and in the UK.[26] Finally, deaths occurring overseas were not taken into account.

The ethnic differentials in mortality in Table 4 are more muted than those that have been estimated from 2001 Census data on limiting long-term illness.[11] In particular, our estimates are inconsistent with more than a modest excess in the mortality of the Pakistani and Bangladeshi groups. The illness-based estimates depend on the assumption that the 
relationship between self-reported health and mortality is invariant across ethnic groups. Evidence from the USA and international comparisons suggest that often it is not.[27, 28 Fig. 1.1.1]

This study finds that SES plays an important role in explaining and offsetting ethnic differences in mortality. Occupational class was not found to account for differentials between groups in earlier studies of immigrants in England and Wales.[2, 4] On the other hand, SES is important is explaining ethnic differentials within Britain in other measures of health.[29, 30] Ethnic groups differ in complex ways in where they live and various aspects of their SES. The set of measures including car ownership considered here may have captured relevant differences in SES better than the occupational class measure used by most earlier studies of migrants or ethnicity and mortality.[26, 31]

Relatively low all-cause mortality in the immigrant population may co-exist with high mortality from particular diseases. Previous research into mortality by own and parents' country of birth using the LS found high mortality, for example from cancer, in the population of Irish origin followed up to 1989, even after controlling for socioeconomic circumstances,[32] and excess mortality from coronary heart disease and cerebrovascular disease for Indian, Pakistani and Bangladeshi men.[33, 7] Both cardiovascular disease and cancer mortality in South Asian migrants and circulatory disease mortality in Caribbean migrants increased with duration of residence in England and Wales over the period 1971-2000.[34, 35] Moreover, large differences exist between ethnic groups in perinatal and infant mortality.[36, 37] For babies born in 2005-2010, infant mortality in both the Pakistani and Caribbean groups was more than twice that of the White British group.[38, 39]

Our hypothesis that the UK-born minority ethnic population would have higher mortality than the White population because of their low SES was supported by the evidence for the Black Caribbean population, but not other minority ethnic groups. Among the UK-born, the Black Caribbean population is older than other non-White groups and one of the larger minority ethnic groups. This finding and the lack of statistical precision in the mortality estimates for other UK-born minority ethnic groups emphasize the need for caution when projecting mortality trends for the minority ethnic population of England and 
Wales.[40] Only after more of the UK-born members of other minority ethnic groups reach ages at which mortality is relatively high, will we discover whether or not they share the low mortality of their immigrant parents. As the immigrant population ages and UK-born minority ethnic population grows, ethnic differentials in mortality are likely to change. Once the 2011 Census data have been linked into the LS, further research based on it using a longer series of death statistics may begin to reveal the nature of these changes.

What is already clear is that, although the selection for good health of the immigrant population offsets this, the low SES of minority ethnic groups has an adverse impact on their mortality. Health interventions focused on specific diseases, conditions and risk factors that are prevalent in particular minority ethnic groups should be complemented by recognition that social disadvantage is a pervasive underlying cause of high all-cause mortality in minority ethnic groups just as it is for the White majority.

Acknowledgements This paper has been cleared for publication by the Office for National Statistics (\#20063C). Permission from them to use the Longitudinal Study is gratefully acknowledged as is the help provided by staff of the Centre for Longitudinal Study Information \& User Support (CeLSIUS). CeLSIUS is supported by the ESRC Census of Population Programme (Award Ref: RES-348-25-0004). The authors alone are responsible for their interpretation of the data. Census output is Crown copyright and is reproduced with the permission of the Controller of HMSO and the Queen's Printer for Scotland. 


\section{What is already known on this subject}

- Immigrants to England and Wales from most places of origin have lower all-cause mortality than the UK-born population.

- This is thought to reflect the selection of immigrants for good health and perhaps the selection of return migrants for poor health.

- Social class has not been found to play an important role in the explanation of differentials in mortality between immigrants and the UK-born population.

\section{What this study adds}

- This is the first detailed study of mortality by self-reported ethnicity in England and Wales that distinguishes the UK-born from the immigrant population of each ethnic group.

- Unlike their immigrant parents or grandparents, the UK-born minority ethnic population does not have lower mortality than UK-born Whites. Moreover, the UKborn Black Caribbean population has substantially higher mortality than UK-born Whites.

- The high mortality of the UK-born Black Caribbean group is accounted for by their low socioeconomic status (SES), as measured by three indicators, and where they live. Low SES also reduces the mortality advantage of the immigrant members of several minority ethnic groups. 


\section{REFERENCES}

1 Harding S, Balarajan R. Mortality data on migrant groups living in England and Wales: issues of adequacy and of interpretation of death rates. In: Haskey J, Huxstep S, eds. Population Projections by Ethnic Group: A Feasibility Study. London: HMSO 2002.

2 Marmot M, Adelstein A, Bulusu L. Immigrant mortality in England and Wales 197078. London: HMSO 1984.

3 Balarajan R, Bulusu L. Mortality among immigrants in England and Wales, 19791983. In: Office for Population Censuses and Surveys, ed. Mortality and Geography: A Review in the mid-1980s. London: HMSO 1990.

4 Harding S, Maxwell R. Differences in mortality of migrants. In: Drever F, Whitehead M, eds. Health Inequalities. London: The Stationery Office 1997:108-21.

5 Wild S, McKeigue P. Cross sectional analysis of mortality by country of birth in England and Wales, 1970-92. Br Med J 1997;314:705-10. doi:10.1136/bmj.314.7082.705 6 Gill PS, Kai J, Bhopal RS, et al. Black and minority ethnic groups. In: Stevens A, Raftery J, Mant J, et al., eds. Health Care Needs Assessment: The Epidemiologically Based Needs Assessment Reviews: Third Series. Milton Keynes: Radcliffe 2007:227-399.

7 Wild SH, Fischbacher C, Brock A, et al. Mortality from all causes and circulatory disease by country of birth in England and Wales 2001-2003. J Public Health 2007;29:1918. doi:10.1093/pubmed/fdm010

8 Marmot M, Adelstein A, Bulusu L. Lessons from the study of immigrant mortality. Lancet 1984;323:1455-7. doi:10.1016/S0140-6736(84)91943-3

9 Razum O, Zeeb H, Akgun HS, et al. Low overall mortality of Turkish residents in Germany persists and extends into a second generation: merely a healthy migrant effect? Trop Med Int Health 1998;3:297-303. doi:10.1046/j.1365-3156.1998.00233.x

10 Abraido-Lanza A, Dohrenwend B, Ng-Mak D, et al. The Latino mortality paradox:a test of the 'salmon bias' and healthy migrant hypotheses. Am J Public Health 1999;89:15438. doi:10.2105/AJPH.89.10.1543

11 Rees PH, Wohland PN, Norman PD. The estimation of mortality for ethnic groups at local scale within the United Kingdom. Soc Sci Med 2009;69:1592-607. doi:10.1016/j.socscimed.2009.08.015 

Quality of Data. London: HMSO 1995.

13 Fox AJ, Goldblatt PO. Longitudinal Study: Socio-demographic mortality differentials. London: HMSO 1982.

14 Fitzpatrick J, Dollamore G. Examining adult mortality rates using the National Statistics Socio-economic Classification. Health Stat Q 1999;2:33-40.

15 Office for National Statistics. The National Statistics Socio-Economic Classification: User Manual. Basingstoke: Palgrave Macmillan 2005.

16 White C, Glickman M, Johnson B, et al. Social inequalities in adult male mortality by the National Statistics Socio-economic Classification, England and Wales, 2001-03. Health Stat $Q$ 2007;36:6-23.

17 Langford A, Johnson B. Social inequalities in adult female mortality by the National Statistics Socio-economic Classification, England and Wales, 2001-03. Health Stat $Q$ 2009;42:6-21.

18 Johnson B, Blackwell L. Review of methods for estimating life expectancy by social class using the ONS Longitudinal Study. Health Stat Q 2007;35:28-36.

19 Kalton G. Handling wave nonresponse in panel surveys. J Off Stat 1986;2:303-14.

20 Little RJA. Modeling the drop-out mechanism in repeated-measures studies. J Am Stat Assoc 1995;90:1112-21. doi:10.1080/01621459.1995.10476615

21 Hogan JW, Roy J, Korkontzelou C. Handling drop-out in longitudinal studies. Stat Med 2004;23:1455-97. doi:10.1002/sim.1728

22 Rao RS, Sigurdson AJ, Doody MM, et al. An application of a weighting method to adjust for nonresponse in standardized incidence ratio analysis of cohort studies. Ann Epidemiol 2005;15:129-36. doi:10.1016/j.annepidem.2004.05.007

23 Little RJA, Rubin DB. Statistical Analysis with Missing Data. New York: Wiley 1987.

24 Christie B. Scotland introduces record of ethnicity on death certificates. $\mathrm{Br} \mathrm{Med} \mathrm{J}$ 2012;344:e475. doi:/10.1136/bmj.e475

25 Smallwood S, Lynch K. An analysis of patient register data in the Longitudinal Study - what does it tell us about the quality of the data? Popul Trends 2010;141:151-69. 
26 Davey-Smith G, Chaturvedi N, Harding S, et al. Ethnic inequalities in health: a review of the UK epidemiological evidence. Crit Public Health 2000;10:375-408.

doi:10.1080/09581590010005331

27 McGee DL, Liao Y, Cao G, et al. Self-reported health status and mortality in a multiethnic US cohort. Am J Epidemiol 1999;149:41-6.

28 OECD. Health at a Glance: Europe 2012. Paris: OECD Publishing 2012. doi:10.1787/9789264183896-en

29 Nazroo JY. The Health of Britain's Ethnic Minorities: Findings from a National Survey. London: Policy Studies Institute 1997.

30 Nazroo JY. The structuring of ethnic inequalities in health: economic position, racial discrimination, and racism. Am J Public Health 2003;93:277-84. doi:10.2105/AJPH.93.2.277 31 Kelaher M, Paul S, Lambert H, et al. The impact of different measures of socioeconomic position on the relationship between ethnicity and health. Ann Epidemiol 2008;18:351-6. doi:10.1016/j.annepidem.2007.12.006

32 Harding S. The incidence of cancers among second-generation Irish living in England and Wales. Br J Cancer 1998;78:958-61. doi:10.1038/bjc.1998.608

33 Harding S. Examining the contribution of social class to high cardiovascular mortality among Indian, Pakistani and Bangladeshi male migrants living in England and Wales. Health Stat $Q$ 2000;5:26-8.

34 Harding S. Mortality of migrants from the Indian Subcontinent to England and Wales: effect of duration of residence. Epidemiology 2003;14:287-92. doi:10.1097/01.EDE.0000050369.88416.82

35 Harding S. Mortality of migrants from the Caribbean to England and Wales: effect of duration of residence. Int J Epidemiol 2004;33:382-6. doi:10.1093/ije/dyh059

36 Collingwood Bakeo A. Investigating variations in infant mortality in England and Wales by mother's country of birth, 1983-2001. Paediatric and Perinatal Epidemiology 2006;20:127-39. doi:10.1111/j.1365-3016.2006.00708.x

37 Balchin I, Whittaker JC, Patel R, et al. Racial variation in the association between gestational age and perinatal mortality: prospective study. Br Med J 2007;334:833. doi:10.1136/bmj.39132.482025.80 
38 Moser K. Gestation-specific infant mortality by social and biological factors among babies born in England and Wales in 2006. Health Stat $Q$ 2009;42:78-87.

39 Office for National Statistics. http://www.ons.gov.uk/ons/rel/child-

health/gestation-specific-infant-mortality-in-england-and-wales/index.html (accessed: 12 Oct 2012).

40 Rees P, Wohland P, Norman P, et al. Ethnic population projections for the UK, 20012051. J Popul Res 2012;29:45-89. doi:10.1007/s12546-011-9076-z 
Table 1 Characteristics of Longitudinal Study members aged <65 in 1991 by ethnic group and place of birth

\begin{tabular}{|c|c|c|c|c|c|}
\hline \multirow[b]{2}{*}{ Ethnic group } & \multirow{2}{*}{$\begin{array}{l}\text { Population } \\
1991 \text { Census }\end{array}$} & \multirow{2}{*}{$\begin{array}{c}\text { Deaths } \\
\text { 1991-2005 }\end{array}$} & \multirow{2}{*}{$\begin{array}{c}\text { \% born in } \\
\text { UK }\end{array}$} & \multicolumn{2}{|c|}{$\%$ aged $65+$ at 1991 Census } \\
\hline & & & & Born in UK & Born abroad \\
\hline White & 403231 & 22318 & 96 & 16.0 & 20.8 \\
\hline Born in UK & 386981 & 21159 & & & \\
\hline Born abroad & 16250 & 1159 & & & \\
\hline All minority ethnic groups & 32964 & 1193 & 42 & 0.6 & 5.0 \\
\hline Born in UK & 13758 & 129 & & & \\
\hline Born abroad & 19206 & 1064 & & & \\
\hline Black Caribbean & 4745 & 241 & 54 & 0.8 & 11.7 \\
\hline Black African & 1875 & 60 & 37 & 0.4 & 2.2 \\
\hline Other Black & 1650 & 19 & 88 & 0.2 & 6.1 \\
\hline Indian & 10502 & 435 & 35 & 0.4 & 5.4 \\
\hline Pakistani & 5915 & 209 & 39 & 0.3 & 2.3 \\
\hline Bangladeshi & 2302 & 86 & 25 & 0.9 & 1.2 \\
\hline Chinese & 1483 & 50 & 28 & 0.5 & 5.5 \\
\hline Other Asian & 1921 & 48 & 23 & 0.2 & 3.8 \\
\hline Other & 2571 & 45 & 63 & 1.4 & 5.8 \\
\hline All ethnic groups & 436195 & 23511 & 92 & 15.6 & 12.9 \\
\hline
\end{tabular}

Source : ONS Longitudinal Study 
Table 2 Percent distribution according to status in 2001 of Longitudinal Study members aged $<65$ in 1991 by ethnic group and place of birth

\begin{tabular}{|c|c|c|c|c|c|c|c|}
\hline \multirow[b]{2}{*}{ Ethnic group/place of } & \multicolumn{5}{|c|}{ Status at 2001 Census } & \multicolumn{2}{|c|}{$\begin{array}{l}\text { Estimated \% of the } \\
\text { exposure of those } \\
\text { unaccounted for that } \\
\text { was lost to emigration }\end{array}$} \\
\hline & Found & Dead & $\begin{array}{c}\text { Reported } \\
\text { embarkations }\end{array}$ & $\begin{array}{l}\text { De- } \\
\text { registered }\end{array}$ & $\begin{array}{l}\text { Unaccounted } \\
\text { for }\end{array}$ & Born in UK & $\begin{array}{c}\text { Born } \\
\text { abroad }\end{array}$ \\
\hline \multicolumn{8}{|l|}{ White } \\
\hline Born in UK & 86.5 & 3.2 & 0.3 & 0.4 & 9.6 & 2 & \\
\hline Born abroad & 70.7 & 4.2 & 2.7 & 4.8 & 17.6 & & 17 \\
\hline \multicolumn{8}{|c|}{ All minority ethnic groups } \\
\hline Born in UK & 74.8 & 0.6 & 0.3 & 1.1 & 23.1 & 4 & \\
\hline Born abroad & 70.4 & 3.3 & 0.9 & 3.3 & 22.1 & & 9 \\
\hline Black Caribbean & 67.0 & 3.1 & 0.8 & 1.9 & 27.2 & 5 & 12 \\
\hline Black African & 60.6 & 1.8 & \multirow{2}{*}{$0.4^{1}$} & 6.1 & 30.8 & 8 & 19 \\
\hline Other Black & 72.5 & 0.7 & & 1.4 & 25.2 & 4 & 10 \\
\hline Indian & 78.9 & 2.5 & 0.4 & 1.3 & 17.0 & 3 & 4 \\
\hline Pakistani & 71.8 & 2.4 & 0.2 & 1.1 & 24.6 & 2 & 5 \\
\hline Bangladeshi & 69.9 & 1.9 & 0.0 & 1.3 & 26.9 & 3 & 5 \\
\hline Chinese & 69.5 & 2.0 & 1.1 & 5.5 & 21.8 & 6 & 16 \\
\hline Other Asian & 65.0 & 1.5 & 3.9 & 7.5 & 22.1 & 8 & 22 \\
\hline Other & 73.3 & 0.9 & 0.9 & 4.3 & 20.7 & 6 & 18 \\
\hline All ethnic groups & 84.9 & 3.2 & 0.4 & 0.7 & 10.8 & 2 & 12 \\
\hline
\end{tabular}

${ }^{1}$ combined in line with ONS disclosure rules.

Source: ONS Longitudinal Study 
Table 3 Percent distribution in the 1991 Census of Longitudinal Study members aged $<65$ according to socioeconomic indicators and place of residence by ethnic group

\begin{tabular}{|c|c|c|c|c|c|c|c|c|c|c|c|c|c|c|c|}
\hline \multirow[b]{3}{*}{ Ethnic group } & \multicolumn{6}{|c|}{ a) Socio-Economic Classification (NS-SEC) } & \multirow{3}{*}{$\begin{array}{l}\text { b) Car } \\
\text { owners }\end{array}$} & \multicolumn{3}{|c|}{ c) Housing tenure } & \multicolumn{4}{|c|}{ d) Area of residence } & \multirow[b]{3}{*}{$\mathbf{N}$} \\
\hline & \multicolumn{2}{|c|}{ Managerial/Prof. ${ }^{1}$} & \multirow[b]{2}{*}{ Interm. $^{2}$} & \multirow[b]{2}{*}{ Lower $^{3}$} & \multirow[b]{2}{*}{ Routine } & \multirow[b]{2}{*}{ Other $^{4}$} & & \multirow{2}{*}{$\begin{array}{c}\text { Owner } \\
\text { occupier }\end{array}$} & \multirow{2}{*}{$\begin{array}{l}\text { Tenant } \\
\text { (social } \\
\text { sector) }\end{array}$} & \multirow{2}{*}{$\begin{array}{c}\text { Tenant } \\
\text { (private } \\
\text { sector) }\end{array}$} & \multirow{2}{*}{$\begin{array}{c}\text { Non- } \\
\text { Metro. }\end{array}$} & \multirow{2}{*}{$\begin{array}{c}\text { Inner } \\
\text { London }\end{array}$} & \multirow{2}{*}{$\begin{array}{c}\text { Outer } \\
\text { London }\end{array}$} & \multirow{2}{*}{$\begin{array}{l}\text { Other } \\
\text { Metro. }\end{array}$} & \\
\hline & Higher & Lower & & & & & & & & & & & & & \\
\hline White & 10.7 & 24.6 & 25.8 & 22.5 & 10.5 & 6.0 & 82.3 & 73.8 & 21.0 & 5.2 & 67.5 & 3.5 & 7.3 & 21.7 & 403,231 \\
\hline $\begin{array}{l}\text { All minority } \\
\text { ethnic groups }\end{array}$ & 8.4 & 14.9 & 22.7 & 24.1 & 13.5 & 16.4 & 67.5 & 68.6 & 24.2 & 7.2 & 29.5 & 19.0 & 23.8 & 27.8 & 32,964 \\
\hline Black Caribbean & 3.2 & 18.1 & 25.5 & 25.5 & 12.2 & 15.4 & 53.3 & 54.0 & 42.2 & 3.8 & 19.6 & 34.2 & 23.7 & 22.4 & 4,745 \\
\hline Black African & 10.5 & 21.8 & 16.5 & 17.9 & 8.7 & 24.6 & 46.8 & 34.8 & 51.3 & 14.0 & 15.5 & 46.7 & 28.3 & 9.4 & 1,875 \\
\hline Other Black & 5.5 & 18.4 & 23.0 & 22.4 & 12.3 & 18.4 & 53.4 & 44.1 & 49.2 & 6.7 & 32.2 & 26.4 & 18.7 & 22.7 & 1,650 \\
\hline Indian & 10.4 & 14.4 & 27.2 & 27.3 & 11.6 & 9.2 & 82.5 & 86.9 & 8.8 & 4.2 & 32.9 & 7.7 & 32.5 & 26.9 & 10,502 \\
\hline Pakistani & 4.4 & 7.3 & 18.5 & 25.4 & 22.0 & 22.4 & 67.5 & 82.7 & 10.8 & 6.6 & 29.9 & 5.8 & 12.5 & 51.8 & 5,915 \\
\hline Bangladeshi & 2.0 & 4.4 & 12.3 & 26.1 & 24.1 & 31.2 & 37.5 & 42.4 & 48.1 & 9.5 & 22.5 & 43.2 & 8.9 & 25.4 & 2,302 \\
\hline Chinese & 13.1 & 14.1 & 30.7 & 20.7 & 5.1 & 16.3 & 78.8 & 64.3 & 24.9 & 10.7 & 43.4 & 19.3 & 19.6 & 17.8 & 1,483 \\
\hline Other Asian & 17.1 & 25.1 & 20.4 & 16.1 & 7.5 & 13.8 & 77.3 & 64.4 & 18.6 & 17.0 & 29.8 & 21.4 & 35.5 & 13.2 & 1,921 \\
\hline Other & 16.1 & 23.6 & 19.7 & 17.3 & 8.2 & 15.1 & 69.9 & 58.1 & 31.0 & 10.9 & 38.7 & 18.3 & 21.8 & 21.2 & 2,571 \\
\hline All ethnic groups & 10.5 & 23.8 & 25.5 & 22.7 & 10.7 & 6.8 & 81.2 & 73.4 & 21.2 & 5.4 & 64.6 & 4.7 & 8.6 & 22.1 & 436,195 \\
\hline
\end{tabular}

${ }^{1}$ Managerial and professional; ${ }^{2}$ Intermediate, including small employers and own account workers; ${ }^{3}$ Lower supervisory \& technical and semi-routine occupations; ${ }^{4}$ Never worked, long-term unemployed, students, and inadequately described occupations.

Source: ONS Longitudinal Study 
Table 4 Relative risks of dying at ages 1-79 in 1991-2005 by place of birth, ethnic group, socioeconomic characteristics and area of residence, each adjusted only for age, sex and period of death, of Longitudinal Study members aged <65 in 1991

\begin{tabular}{|c|c|c|c|c|c|}
\hline & Rate ratio & $95 \% \mathrm{Cl}$ & & Rate ratio & $95 \% \mathrm{Cl}$ \\
\hline Place of birth & & & Socio-Economic Classification & & \\
\hline Born in the UK & 1 & & Higher managerial \& professional & 1 & \\
\hline \multirow[t]{2}{*}{ Born abroad } & 0.91 & (0.87 to 0.95$)$ & Lower managerial \& professional & 1.21 & (1.14 to 1.28$)$ \\
\hline & & & Intermediate & 1.40 & (1.32 to 1.48$)$ \\
\hline Ethnic group & & & Lower & 1.75 & (1.65 to 1.86$)$ \\
\hline White & 1 & & Routine & 2.15 & (2.02 to 2.28$)$ \\
\hline Black Caribbean & 0.88 & (0.77 to 0.99$)$ & Other & 3.03 & (2.85 to 3.22$)$ \\
\hline Black African & 1.05 & (0.81 to 1.35$)$ & & & \\
\hline Other Black & 0.79 & (0.50 to 1.24$)$ & Car ownership & & \\
\hline Indian & 0.91 & (0.83 to 1.00$)$ & $1+$ cars & 1 & \\
\hline Pakistani & 0.96 & (0.84 to 1.10$)$ & No car & 1.93 & (1.88 to 1.98$)$ \\
\hline Bangladeshi & 0.99 & (0.80 to 1.22 ) & & & \\
\hline Chinese & 0.81 & (0.61 to 1.07 ) & Housing tenure & & \\
\hline Other Asian & 0.65 & (0.49 to 0.87 ) & Owner occupier & 1 & \\
\hline \multirow[t]{2}{*}{ Other } & 0.72 & (0.54 to 0.97 ) & Tenant - social & 1.91 & (1.86 to 1.97 ) \\
\hline & & & Tenant - private & 1.53 & (1.44 to 1.62$)$ \\
\hline \multicolumn{6}{|l|}{ Area of residence } \\
\hline Non-Metropolitan & 1 & & & & \\
\hline Inner London & 1.22 & (1.15 to 1.29 ) & & & \\
\hline Outer London & 0.95 & (0.90 to 1.00$)$ & & & \\
\hline Other Metropolitan & 1.20 & (1.17 to 1.24$)$ & & & \\
\hline
\end{tabular}

Source: ONS Longitudinal Study 
Table 5 Relative risks (RR) of dying at ages 1-79 in 1991-2005 by place of birth and ethnic group of Longitudinal Study members aged $<65$ in 1991

\begin{tabular}{|c|c|c|c|c|c|c|}
\hline & \multicolumn{2}{|c|}{$\begin{array}{l}\text { Model 1: Age, sex, and } \\
\text { period adjusted RR }\end{array}$} & \multicolumn{2}{|c|}{$\begin{array}{l}\text { Model 2: RR also adjusted } \\
\text { for SES \& residence }\end{array}$} & \multicolumn{2}{|c|}{$\begin{array}{l}\text { Model 3: RR further adjusted } \\
\text { for unobserved embarkations }\end{array}$} \\
\hline & Rate ratio & $95 \% \mathrm{Cl}$ & Rate ratio & $95 \% \mathrm{Cl}$ & Rate ratio & $95 \% \mathrm{Cl}$ \\
\hline \multicolumn{7}{|c|}{ Place of birth and ethnic group } \\
\hline \multicolumn{7}{|l|}{ Born in the UK } \\
\hline White & 1 & & 1 & & 1 & \\
\hline Black Caribbean & 1.38 & (1.03 to 1.86$)$ & $1.03^{*}$ & (0.76 to 1.38$)$ & $1.03 *$ & (0.77 to 1.39$)$ \\
\hline Black African & 1.13 & (0.56 to 2.26$)$ & 0.88 & (0.44 to 1.76$)$ & 0.89 & (0.45 to 1.79$)$ \\
\hline Other Black & 0.89 & (0.51 to 1.58$)$ & 0.68 & (0.39 to 1.20$)$ & 0.68 & (0.39 to 1.20$)$ \\
\hline Indian & 0.88 & (0.59 to 1.31$)$ & 0.83 & (0.55 to 1.23$)$ & 0.83 & (0.55 to 1.24$)$ \\
\hline Pakistani & 0.99 & (0.60 to 1.62$)$ & 0.83 & (0.51 to 1.36$)$ & 0.83 & (0.51 to 1.36$)$ \\
\hline Bangladeshi & 0.55 & (0.14 to 2.19 ) & 0.36 & (0.09 to 1.43$)$ & 0.36 & (0.09 to 1.43 ) \\
\hline Chinese & 0.81 & (0.26 to 2.51$)$ & 0.76 & (0.24 to 2.35$)$ & 0.77 & (0.25 to 2.38$)$ \\
\hline Other Asian & 0.46 & (0.11 to 1.83 ) & 0.43 & (0.11 to 1.76$)$ & 0.43 & (0.11 to 1.74 ) \\
\hline Other & 0.86 & (0.53 to 1.41 ) & 0.78 & (0.48 to 1.28$)$ & 0.79 & (0.48 to 1.28 ) \\
\hline \multicolumn{7}{|l|}{ Born abroad } \\
\hline White & 0.94 & (0.88 to 0.99 ) & 0.90 & (0.84 to 0.95$)$ & 0.91 & (0.85 to 0.96$)$ \\
\hline Black Caribbean & 0.80 & (0.70 to 0.93 ) & $0.64^{*}$ & (0.56 to 0.74$)$ & $0.66^{*}$ & (0.57 to 0.76$)$ \\
\hline Black African & 1.03 & (0.79 to 1.35 ) & 0.76 & (0.58 to 1.00$)$ & 0.79 & (0.60 to 1.04 ) \\
\hline Other Black & 0.66 & (0.31 to 1.38 ) & 0.57 & (0.27 to 1.21$)$ & 0.58 & (0.28 to 1.21$)$ \\
\hline Indian & 0.91 & (0.82 to 1.00$)$ & 0.88 & (0.80 to 0.98$)$ & 0.89 & (0.80 to 0.98$)$ \\
\hline Pakistani & 0.95 & (0.83 to 1.10 ) & 0.78 & (0.68 to 0.90$)$ & 0.79 & (0.68 to 0.91$)$ \\
\hline Bangladeshi & 1.01 & (0.81 to 1.25 ) & 0.59 & (0.48 to 0.74$)$ & 0.59 & (0.48 to 0.74$)$ \\
\hline Chinese & 0.81 & (0.61 to 1.08 ) & 0.68 & (0.51 to 0.91 ) & 0.70 & (0.52 to 0.93 ) \\
\hline Other Asian & 0.66 & (0.50 to 0.89$)$ & 0.62 & (0.47 to 0.83$)$ & 0.65 & (0.48 to 0.86$)$ \\
\hline Other & 0.66 & (0.46 to 0.95$)$ & 0.62 & (0.43 to 0.90$)$ & 0.63 & (0.44 to 0.91$)$ \\
\hline \multicolumn{7}{|l|}{ Car ownership } \\
\hline $1+$ cars & & & 1 & & 1 & \\
\hline No car & & & 1.40 & (1.36 to 1.45 ) & 1.40 & (1.36 to 1.45 ) \\
\hline \multicolumn{7}{|l|}{ Housing tenure } \\
\hline Owner occupier & & & 1 & & 1 & \\
\hline Tenant - social & & & 1.41 & (1.36 to 1.45$)$ & 1.41 & (1.36 to 1.45$)$ \\
\hline Tenant - private & & & 1.27 & (1.19 to 1.35$)$ & 1.28 & (1.20 to 1.36$)$ \\
\hline \multicolumn{7}{|c|}{ Socio-Economic Classification } \\
\hline Higher managerial $\&$ & professional & & 1 & & 1 & \\
\hline Lower managerial \& & rofessional & & 1.17 & (1.10 to 1.24$)$ & 1.17 & (1.10 to 1.24$)$ \\
\hline Intermediate & & & 1.31 & (1.24 to 1.39$)$ & 1.31 & (1.24 to 1.39$)$ \\
\hline Lower & & & 1.47 & (1.39 to 1.56$)$ & 1.47 & (1.39 to 1.56$)$ \\
\hline Routine & & & 1.66 & (1.55 to 1.77$)$ & 1.66 & (1.55 to 1.76$)$ \\
\hline Other & & & 2.14 & (2.00 to 2.28$)$ & 2.14 & (2.00 to 2.29 ) \\
\hline \multicolumn{7}{|l|}{ Area of residence } \\
\hline Non-Metropolitan & & & 1 & & 1 & \\
\hline Inner London & & & 1.01 & (0.95 to 1.08$)$ & 1.02 & (0.96 to 1.09 ) \\
\hline Outer London & & & 0.99 & (0.94 to 1.04$)$ & 0.99 & (0.94 to 1.04$)$ \\
\hline Other Metropolitan & & & 1.06 & (1.03 to 1.10$)$ & 1.06 & (1.03 to 1.10$)$ \\
\hline
\end{tabular}

* Ratio of Black Caribbean Born in UK/Born abroad, Model 2: $P=0.005$; Model 3: $P=0.007$.

Source: ONS Longitudinal Study 